\title{
Attenuation of ultraviolet radiation reaching the surface due to atmospheric aerosols in Guangzhou
}

\author{
DENG XueJiao ${ }^{1 *}$, ZHOU XiuJi $^{2}$, TIE XueXi ${ }^{3}$, WU Dui ${ }^{1}$, LI Fei $^{1}$, TAN HaoBo $^{1} \&$ DENG Tao ${ }^{1}$ \\ ${ }^{1}$ Institute of Tropical and Marine Meteorology, China Meteorological Administration, Guangzhou 510080, China; \\ ${ }^{2}$ Chinese Academy of Meteorological Sciences, China Meteorological Administration, Beijing 100081, China; \\ ${ }^{3}$ National Center for Atmospheric Research, Boulder, CO 80307, USA
}

Received July 14, 2011; accepted January 16, 2012; published online May 15, 2012

\begin{abstract}
The UV attenuation due to atmospheric aerosols in Guangzhou was quantitatively assessed using surface ultraviolet radiation (UV, 295-385 nm) observation, sun photometer and radiation models. Observations showed that the annual average value of aerosol optical depth (AOD) was 1.19 in UV spectral region of $340 \mathrm{~nm}$, the annual average occurrence frequency of aerosol optical depth $\mathrm{AOD}_{340 \mathrm{~nm}}>1.0$ was $55 \%$, and the annual average attenuation rate of surface UV direct radiation of $340 \mathrm{~nm}$ was $68 \%$. It was proven in the observation of surface UV radiation and model evaluation that annual average attenuation of UV due to atmosphere was $75 \%$, and that reached $72 \%$ in the dry season (October, November, December and January); while average attenuation of UV due to atmospheric aerosols reached $62 \%$ in the dry season. It was indicated that very significant UV attenuations due to atmospheric aerosols existed in Guangzhou urban agglomeration, and at least half of UV radiation was attenuated due to atmospheric aerosols. Such large-amplitude attenuation will have a significant impact on urban ecosystem and species chemical cycles, especially photochemical reaction processes.
\end{abstract}

aerosol optical depth, attenuation rate, ultraviolet radiation, atmospheric aerosols

Citation: Deng X J, Zhou X J, Tie X X, et al. Attenuation of ultraviolet radiation reaching the surface due to atmospheric aerosols in Guangzhou. Chin Sci Bull, 2012, 57: 2759-2766, doi: 10.1007/s11434-012-5172-5

Clouds and aerosols are the most important factors affecting the solar radiation reaching the surface [1,2], and play an important role in the earth climate system. Currently, the disturbance of high-concentration anthropogenic aerosols resulting from urbanization to the earth-atmosphere radiation system is significant $[3,4]$. It also affects the amount of UV radiation reaching the ground, which has a significant impact on urban ecosystems, species chemical cycle, especially photochemical reactions $[5,6]$. UV radiation is the energy driving source of atmospheric photochemical reactions, and plays a key role in the formation of $\mathrm{OH}$ free radicals and ozone. Take following situations as examples: 305-320 nm wavelength of light makes the $\mathrm{O}_{3}$ photolysis occur, free radicals produced during which are important sources of $\mathrm{OH}$ free radicals; 310-396 nm wavelength of

*Corresponding author (email: dxj@grmc.gov.cn) light makes the $\mathrm{HNO}_{2}$ photolysis occur, during which $\mathrm{OH}$ free radicals are produced directly; 190-350 nm wavelength of light makes the $\mathrm{H}_{2} \mathrm{O}_{2}$ photolysis occur, during which $\mathrm{OH}$ free radicals are produced directly; 301-356 nm wavelength of light makes the $\mathrm{CH}_{2} \mathrm{O}$ photolysis occur, $\mathrm{H}$ free radicals produced during which are important sources of $\mathrm{HO}_{2}$ free radicals; 202-422 nm wavelength of light makes the $\mathrm{NO}_{2}$ photolysis occur, which is an important part of the formation of $\mathrm{O}_{3}$. Therefore, factors affecting UV radiation will also affect the formation yield of $\mathrm{OH}$ free radicals and $\mathrm{O}_{3}$, and then affect the atmospheric substance circulation system. Especially in the metropolitan region, the impact of high-concentration aerosols on UV radiation and urban substance recycling ecosystems should be taken seriously enough.

In recent years, international pollution research on the urban agglomeration has been markedly strengthened. For 
this reason, urban meteorological and environmental research programs (GURME) and research response were established by World Meteorological Organization (WMO, 2001) [7]. In 2004, scientists from China and the United States launched a joint observational study program of troposphere aerosols in East Asia [8], and analyzed the characteristic of aerosols and its impact on surface solar shortwave radiation and UV radiation quantitatively in parts of China. The results show that aerosols have a significant attenuation effect on solar radiation in northern China $[9,10]$. In the past the problem of urban aerosols pollution was mainly focused on scattering (such as sulphate) aerosols. Recent researchers began to pay attention to absorbent (such as black carbon) aerosols, organic carbon aerosols and the impact of aerosol indirect effect on solar radiation, atmospheric photolysis and $\mathrm{O}_{3}$ formation [11-13]. In 1977, Dave considered the impact of aerosols when measured UV radiation to estimate the total amount of ozone in atmospheric column [14]. In 1980, Anita studied the impact of atmospheric turbidity and haze on UV radiation in New York [15]. In 1998, Richard and Gordon [16] studied the estimation of UVB in different cloud conditions. Lyamani et al. [17] studied the microphysical vertical properties and radiative forcing of aerosol in southeastern Spain in 2003. Tie et al. [18,19] studied the impact of global cloud and aerosols on UV and ozone. The results show that the impact of cloud and aerosols on UV radiation is significant, and there is apparent characteristic of space and time variation.

In recent years, China also concerns about the study of the air pollution impact on UV radiation increasingly. For example, the maximum reduced rate of UV radiation at the ground is $50 \%$ in Beijing city because of the impact of air pollution [20]; the percentage of ultraviolet radiation intensity decrease is nearly half in Shanghai each month, when the visibility is less than $2500 \mathrm{~m}$. While in general, the past ultraviolet radiation observation studies in Beijing, Shanghai and Guangzhou [21-24] were mainly for the size of the UV radiation itself. The attenuation problem of UV radiation due to atmospheric aerosols still lacks quantitative analysis in Chinese urban agglomeration region. In present, atmospheric aerosols is the primary pollutant of air pollution in Guangzhou. The observation facts show that there is apparent characterization expression of aerosol impact on ozone productivity through attenuation of UV radiation [25], and the preliminary model verification has been derived $[6,26]$. The impact of serious aerosol pollution on UV radiation in Guangzhou is studied in this paper, making use of surface UV radiation observational data, aerosol optical thickness data observed through the sun photometer and NCAR TUV radiation model during recent years. The attenuation share of surface UV radiation due to atmospheric aerosols is analyzed in detail in the dry season (autumn and winter, October, November, December, and January) when heavy pollution often appears in Guangzhou urban agglomeration particularly.

\section{Applied data and NCAR TUV radiation model comparison of simulation and observation}

UV radiation data series in 2000, 2004 and 2006 are analyzed statistically in this paper. The TUVR radiometer of American Eppley lab is used to observe data, which is used to observe UV radiation by many domestic and foreign research units [27,28]. Its measurement range is $295-385 \mathrm{~nm}$, and the data acquisition collects the average of values measured 5 times per minute as total UV radiation. At present, there is no measurement standard for solar UV irradiance in China. When the imported UV radiometer is beyond the prescribed period (usually one year), it can only be returned to the country of origin to re-calibrate, or carried out unified contrast observation calibration using the recognized and common standard radiometer. The three-year UV radiation observation data adopted in this paper are observed through Eppley TUVR new radiometers numbered 32132, 33543 and 34192 for a year, in order to ensure the quality of observation data. The detailed performance introduction and error source analysis of TUVR UV radiometer can be found in the article by Tan et al. [29]. Microtops II sun photometer of American Solar Light Company is used to observe aerosol optical depth, which has five wave bands and the wave length is $340,500,870,936$ and $1020 \mathrm{~nm}$, respectively, the half wave width is $10 \mathrm{~nm}$ and the viewing angle is $2.5^{\circ}$. Sun photometer observation requires no clouds block the Sun's surface, so the observation time is not continuous. Analysis of the results represents the AOD situation in cloud-free weather conditions. The observation error is the main source of the AOD uncertainty, which is resulted from the sun aiming accuracy [30] and the cloud screening. The fixed frame and the increasing measurement number can reduce the observation error effectively. The cloud detection scheme presented by Smirnov et al. [31] can be referred, that is, the average of continuous is considered in each observation, if the 5-group readings fluctuate and their deviation is more than 0.03 , then it is believed that the targeting bias exists or clouds block the sun. The inversion calculation and Langley calibration of aerosol optical depth through the sun photometer can be found in the articles by Bi et al. [32] and Tan et al. [33], respectively. The calibration result using the Langley method through the sun photometer has little difference with the factory calibration in this paper, and the factory calibration value is slightly larger than the calibration result. The possible reason is that the aging of filter or photoelectric sensor makes the amount of radiation received or the voltages transformed by the photoelectric sensor reduce, while the total error is less than $2 \%$, which shows the instrument stability is good and the observation result is reliable. The monthly variation characteristic and the direct radiation transmittance calculation of the aerosol optical depth in the $340 \mathrm{~nm}$ UV spectral region for three years (2004, 2005 and 2006) are analyzed in this paper. The observation site of UV radiation and sun photometer locates in the Guangdong 
Meteorological Bureau 20-storey roof $\left(113^{\circ} 18^{\prime} \mathrm{E}, 23^{\circ} 08^{\prime} \mathrm{N}\right)$, where the altitude is about $98 \mathrm{~m}$ and the height from the ground is $70 \mathrm{~m}$. The observation point locates in Yuexiu District, Guangzhou City, which belongs to the city center.

NCAR TUV (National Center of Atmospheric Research Troposphere, Ultraviolet and Visible Radiation Model) is adopted in this paper, which is a radiative transfer model to calculate the troposphere UV radiation and part of the visible radiation developed by Madronich and Flocke [34]. in NCAR. The model wavelength range is $121-735 \mathrm{~nm}$, and solves the radiative transfer equation adopting 2 or $n$ stream flow program. TUV model was used to calculate global direct radiation, diffuse radiation, and actinic flux by Mayer et al. [35]. Castro et al. [36] calculated $\mathrm{NO}_{2}$ photochemical rate coefficients $\mathrm{J}\left[\mathrm{NO}_{2}\right]$ using TUV model and observed it through instrument, finding that results coincide well by the two methods if boundary layer aerosol distribution is considered. Researches were completed in 2008 [37] by the author through a large number of comparative analyses about UV radiation observation and TUV model simulation in Guangzhou. The results show that the surface UV radiation can be calculated accurately using TUV model only when reasonable aerosol radiative property parameters (optical depth, single scattering factor SSA, etc.) are input. For example, TUV model calculations of the clean and pollution process were very consistent with the observed UV radiation results when inputting measured parameters such as aerosol optical depth, etc. during December 17-27, 2006.

UV radiation flux is solved using TUV radiation model in this paper. The model setting standard atmospheric profile is taken as input in calculation, and the total amount of ozone comes from satellite observation (as shown in Figure 1). The integral spectral region coincides with the monitoring wavelength through Eppley TUVR radiometer, that is, 295-385 $\mathrm{nm}$. UV radiation undergoes scattering and absorption attenuation through the atmosphere to the surface due to cloud, aerosol and air molecule, among which air atmospheric ozone and pollution gases $\left(\mathrm{NO}_{2}, \mathrm{SO}_{2}\right)$ of air molecules, especially stratospheric ozone layers absorb lots of UV radiation, so that UV radiation less than $290 \mathrm{~nm}$ can not reach the surface basically. Research has shown that UV radiation reaching the surface is mainly due to cloud and aerosol (not ozone) effects [38,39], and aerosol has greater attenuation effect on the surface UV radiation $(>315 \mathrm{~nm})$ than ozone does in cloud-free case [40,41]. The attenuation contrast of the total UV radiation reaching the surface due to $\mathrm{AOD}, \mathrm{O}_{3}, \mathrm{NO}_{2}$ and $\mathrm{SO}_{2}$ in different concentration levels is shown in Figure 2, from which it can be seen that UV radiation of surface observation is mainly caused by aerosol attenuation. Therefore, aerosol attenuation must be considered to calculate the surface UV radiation accurately. Calculations show that surface UV attenuations caused by the total amount of $300 \mathrm{DU}$ and $500 \mathrm{DU} \mathrm{O}_{3}$ have little difference. Calculated results of different total $\mathrm{SO}_{2}$ overlap to a line, it shows that the attenuation of surface UV radiation due to $\mathrm{SO}_{2}$ can be neglected. Figure 1 shows that ozone in Guangzhou is 234-296 DU. UV radiation attenuation caused by ozone and other pollutants is small relative to that caused by the current high-concentration aerosol pollution in Guangzhou. The pollution gases $\left(\mathrm{SO}_{2}, \mathrm{NO}_{2}\right)$ affecting UV radiation are not considered relative to ozone and aerosols in this paper, so the error exists. It is less than $5 \%$ through attenuation comparative analysis of UV radiation due to different concentration-level $\mathrm{SO}_{2}$ and $\mathrm{NO}_{2}$ using TUV model.

\section{Optical depth and direct radiation attenuation rate of aerosols in $\mathrm{UV}$ spectral region}

UV radiation of ground-based observation is divided into two parts, that is, the direct radiation and scattered radiation. The attenuation of the direct radiation due to atmospheric

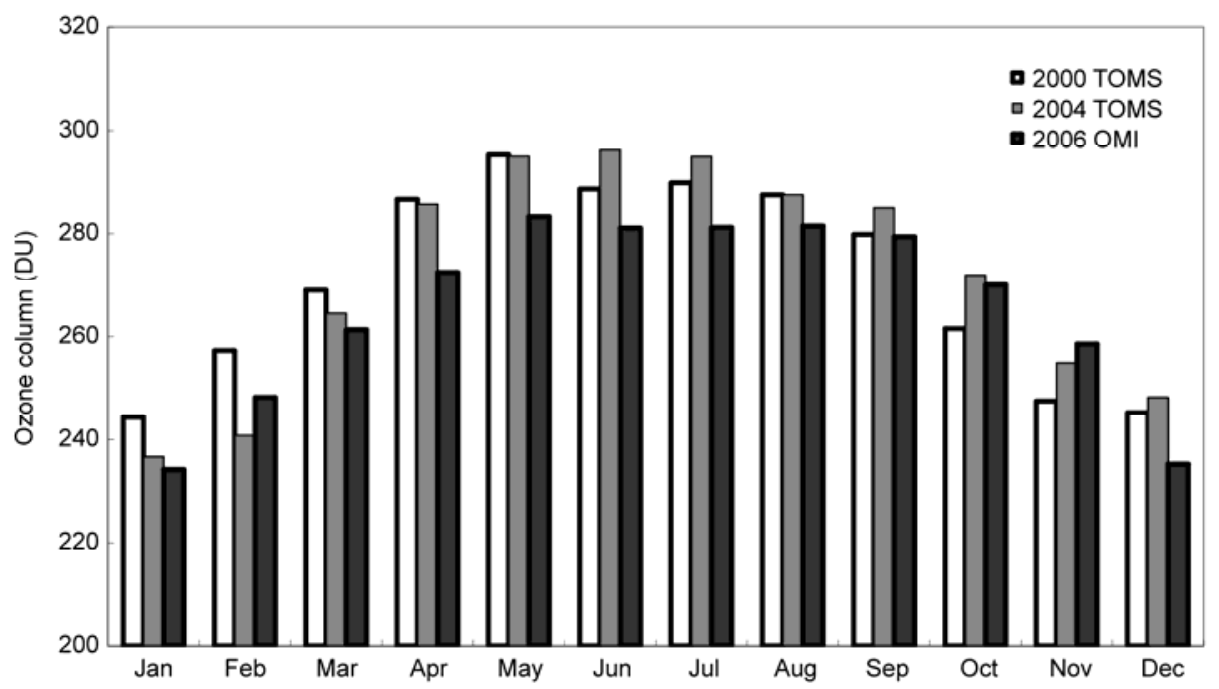

Figure 1 Monthly variation of total ozone observed by satellite in Guangzhou. Data of 2000 and 2004 come from the TOMS; data of 2006 come from the OMI. 

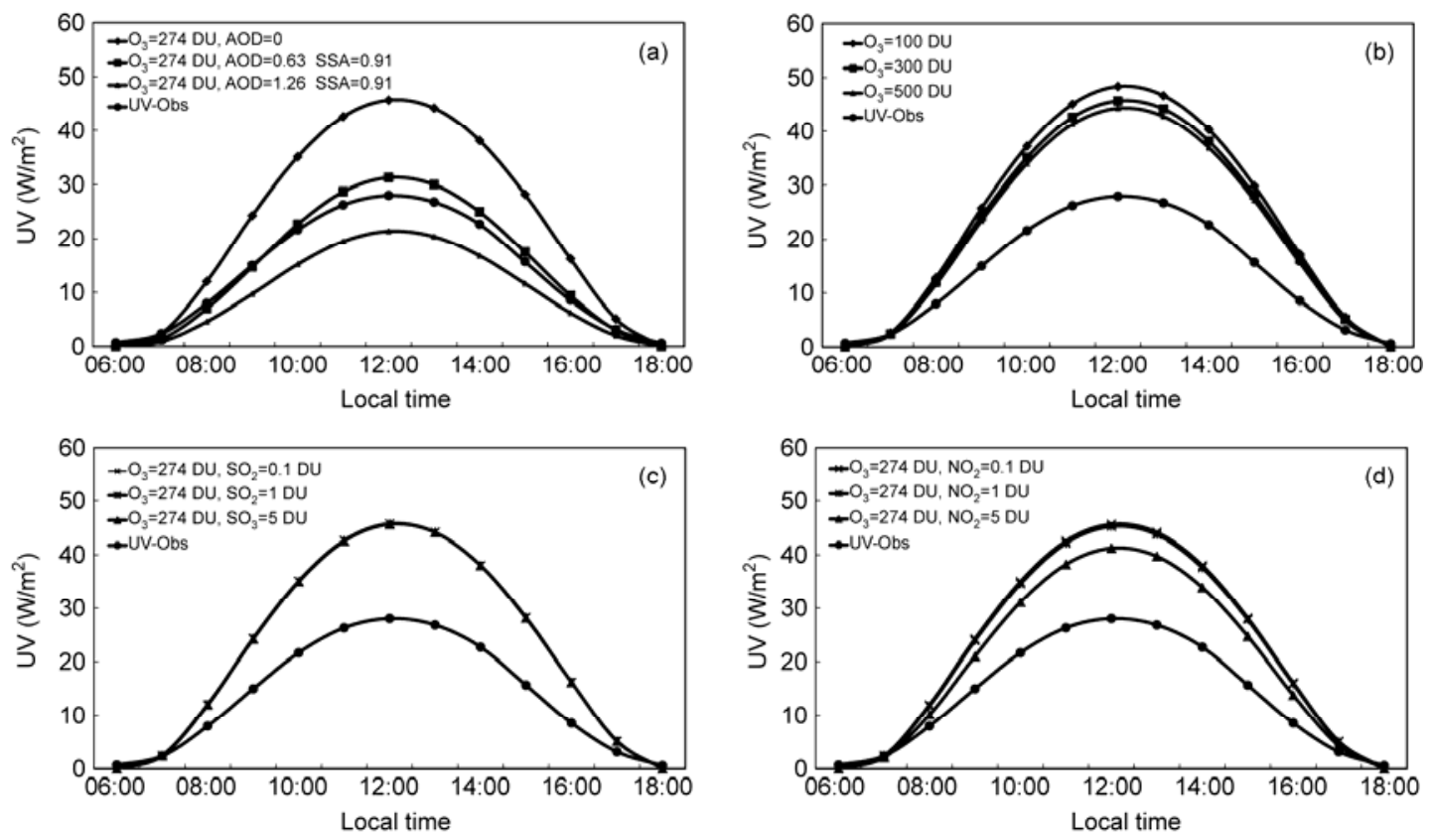

Figure 2 The attenuation contrast of the total UV radiation reaching the surface due to aerosol optical depth $\mathrm{AOD}$ (a), $\mathrm{O}_{3}$ (b), $\mathrm{SO}_{2}$ (c), $\mathrm{NO}_{2}$ (d) in different concentration levels (ozone column content is 274 DU on November 7, 2006).

aerosols only depends on the aerosol optical depth (AOD). The AOD numeric value indicates the aerosol content in the atmospheric column, which is a fundamental physical quantity of atmospheric turbidity. Monthly variation of $340 \mathrm{~nm}$ aerosol optical depth observed in the noon in Guangzhou is shown in Figure 3, from which it can be seen that AOD average value variation range of all months throughout a year is $0.67-1.74$, its minimum variation range is $0.28-0.97$ and its maximum variation range is $1.44-2.87$; AOD value in March is the highest during the first half year, the average value is 1.74 and the highest value is up to 2.67 ; the next highest AOD value is in October during the second half year, the average value is 1.31 and the highest value is up to 2.80 ; AOD value in May is the lowest during a year, the average value is 0.67 and the highest value is only 1.44. At present, the average annual occurrence frequency of $340 \mathrm{~nm}$ aerosol optical depth AOD $>1$ is $55 \%$ in Guangzhou, and the annual average value is 1.19 . The observational characteristics of aerosol optical depth in Guangzhou can be found in detail in the article by Tan [33]. A larger AOD value in spring (March and April) may be related to hydrophilic growth of aerosol particles caused by larger relative humidity. Furthermore, it also may be related to long-range transport of pollutants in Southeast Asia for spring is the season when biomass of Southeast Asia burn [42]. While a larger AOD value in autumn may have something to do with pollution accumulation in weather conditions of weaker advection and turbulent diffusion. In general, it is believed that the low (high) AOD value is associated with clean (pollution) weather. It can be seen from Figure 3 that the difference between the maximum and minimum is smaller only in May and June while it is larger in all other months, which indicates that cleaner and more pollution process both appear in most months of a year in Guangzhou; AOD value is the highest in October and the difference between the maximum and minimum is the largest, which indicates that the pollution process in October is fairly obvious; there is a similar situation in March and April, but October is apparent "dry aerosol" pollution month belonging to "dry season", while March and April are "wet aerosol" pollution months belonging to "wet season". A larger AOD value in March and April may be closely related to aerosol hygroscopic growth effect.

According to Ångström function relationship: $\mathrm{AOD}_{1} /$ $\mathrm{AOD}_{2}=\left(\lambda_{2} / \lambda_{1}\right)^{\alpha}$, the wavelength index $\alpha$ is about $1.4 \mathrm{ob}-$ served in Guangzhou [37], which shows that visible aerosol optical depth has non-linear characteristics with wavelength.

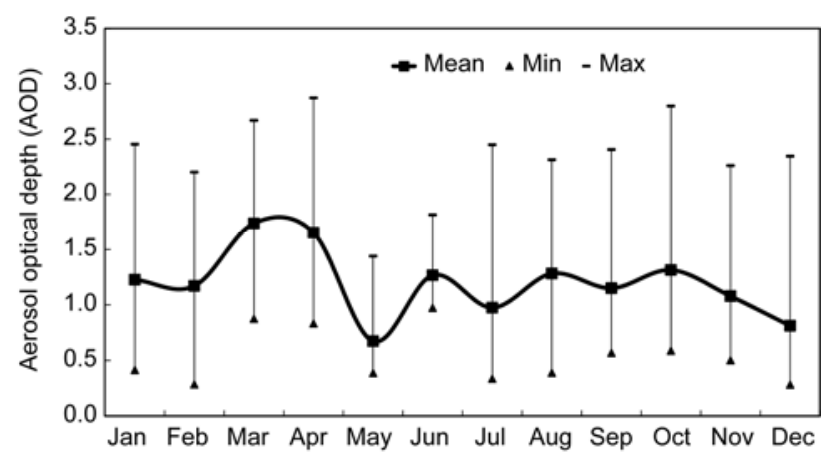

Figure 3 Monthly variation of $340 \mathrm{~nm}$ aerosol optical depth observed in Guangzhou. 
The larger the wavelength is, the smaller the corresponding optical depth is, and the relationship presents $\alpha$ exponential attenuation. In fact, the radiation less than $290 \mathrm{~nm}$ can not reach the ground already. The direct UV radiation attenuation rate of $340 \mathrm{~nm}$ observed by sun photometer and that of some UV wave bands derived from Ångström function relationship are shown in Figure 4, which indicates that the variation characteristics of attenuation rate and aerosol optical depth are consistent. The more aerosols are, the larger AOD numerical value is, and the stronger the attenuation of direct radiation is. For example, the AOD numerical values are larger in March and April, and the direct radiation attenuation rate is larger too. Evenly throughout the year, $340 \mathrm{~nm}$ direct radiation attenuation rate observed actually is up to $68 \%$; calculated $300,350,400$ and $450 \mathrm{~nm}$ average optical depth is $1.42,1.15,0.95$ and 0.81 , respectively, and the corresponding direct UV radiation attenuation rate is up to $74 \%$, $67 \%, 60 \%$ and 54\%, respectively. It indicates that in the current pollution situation in Guangzhou, the attenuation of UV radiation due to aerosols is very significant, and at least more than half direct UV radiation is attenuated by aerosols.

\section{The attenuation rate of the total surface UV radiation due to actual atmosphere}

The average monthly changes of UV radiation (295-385 nm) observed in 2000, 2004 and 2006 are shown in Figure 5, from which it can be seen that UV radiation is the strongest in summer during a year, followed by autumn and winter. The monthly average radiation maximum occurs in July during a year, and the (295-385 nm) wave band 06:00$18: 00,10: 00-14: 00,12: 00$ average is $10.0,16.0,17.3 \mathrm{~W} / \mathrm{m}^{2}$, respectively; radiation minimum occurs in March, and the (295-385 nm) wave band 06:00-18:00, 10:00-14:00, 12:00 monthly average is $4.0,7.1,7.6 \mathrm{~W} / \mathrm{m}^{2}$, respectively. It also can be seen from Figure 5 that 06:00-18:00, 10:00-14:00, 12:00 average UV radiation changes in shape are very similar, especially 10:00-14:00, 12:00 average UV radiation only have some minor differences in value; the ratio of 10:00-

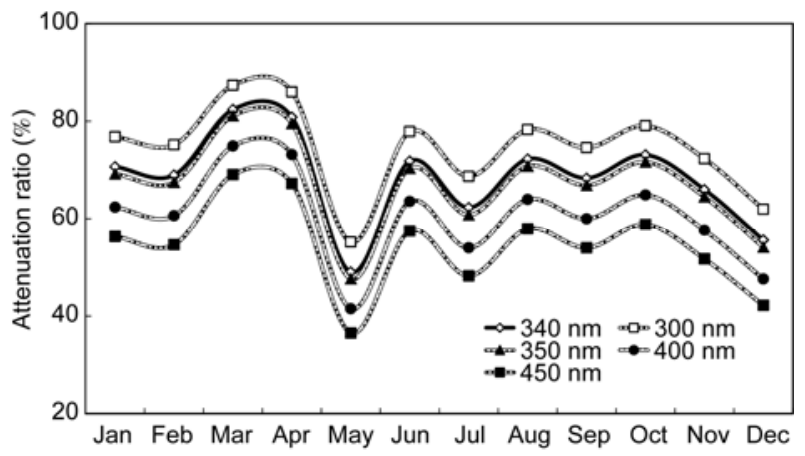

Figure 4 Attenuation rate of direct UV radiation due to aerosols in Guangzhou (1-exp (-AOD)).
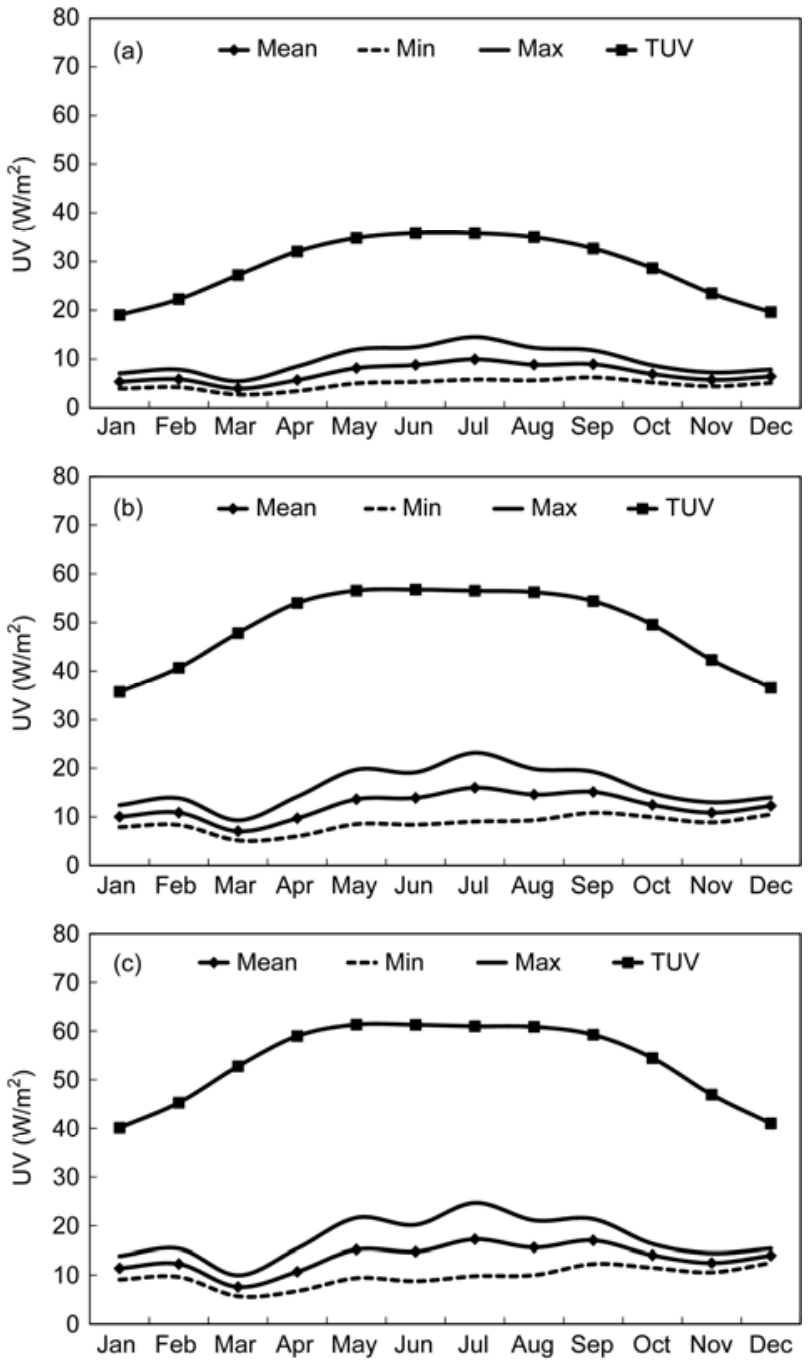

Figure 5 Monthly variation of the total UV radiation $(295-385 \mathrm{~nm}$ ) observed actually. (a) 06:00-18:00; (b) 10:00-14:00; (c) 12:00.

14:00 average UV radiation to that of 12:00 varies between 0.87 and 0.94 , indicating that $\mathrm{UV}$ radiation is the strongest in the noon, while 10:00-14:00 radiation before and after noon only varies between the $13 \%$ maximum. TUV in Figure 5 represents the corresponding spectral UV radiation calculated in the case of cloud-free and no-aerosol using the TUV model. Compare the strongest surface UV radiation calculated in the theoretical model with that derived in actual, and the difference between them is significant, which indicates that the attenuation of UV radiation due to actual atmosphere (clouds and aerosols) is fairly apparent.

The radiation observed by the ground radiometer is that reaching the ground after the solar radiation extinction (scattering, absorption) effect through a whole layer of the atmosphere, that is, sum of the direct radiation and diffuse radiation (downward irradiance intensity). The radiation attenuation factors such as clouds and aerosols etc. may exist in the sky when observing actually, and the radiation observed is a result affected by a variety of attenuation fac- 
tors collectively. The actually observed radiation is through the attenuation of a variety of atmospheric factors (air molecules, clouds and aerosols, etc.), and the UV radiation attenuation rate $\left(\mathrm{UV}_{\mathrm{AR}}\right)$ of atmosphere can be expressed as

$$
\mathrm{UV}_{\mathrm{AR}}=\left(\mathrm{UV}_{\mathrm{tuv}}-\mathrm{UV}_{\mathrm{obs}}\right) / \mathrm{UV}_{\mathrm{tuv}} \times 100 \% \text {, }
$$

where $\mathrm{UV}_{\text {tuv }}$ represents the maximum available surface radiation calculated in the case of cloud-free and no-aerosol using radiation model, and $\mathrm{UV}_{\mathrm{obs}}$ represents the surface $\mathrm{UV}$ radiation observed actually. The numerical value of UV radiation attenuation ratio $\mathrm{UV}_{\mathrm{AR}}$ characterizes the attenuation extent of the surface UV total radiation due to the actual atmosphere.

The monthly variation of UV radiation attenuation rate due to actual atmosphere $\mathrm{UV}_{\mathrm{AR}}$ is shown in Figure 6, from which it can be seen that the average attenuation rate in different time periods (06:00-18:00, 10:00-14:00, 12:00) throughout the year is very close, and it has relative significant difference only in October and November; the attenuation rate throughout a year varies between $86 \%$ and $66 \%$, the maximum is $86 \%$ in March, the second maximum is $82 \%$ in April, and the minimum is $66 \%$ in December; the attenuation rate in other months (January, February, May and November) varies between $71 \%-75 \%$, and the average attenuation rate in the dry season (October, November, December and January) is $72 \%$; $75 \%$ of UV radiation can not reach the ground throughout the year averagely, and the attenuation rate is the maximum of the second half year in October and November particularly. It can be seen that the current attenuation of UV radiation due to the actual atmosphere in Guangzhou is very apparent, which is mainly caused by scattering and absorption of clouds and aerosols.

\section{Attenuation rate of the total surface UV radia- tion due to atmospheric aerosols in cloud-free days}

The solar radiation is attenuated by atmospheric aerosols through absorption and scattering effect, the process of which depends on the aerosol particle size and chemical

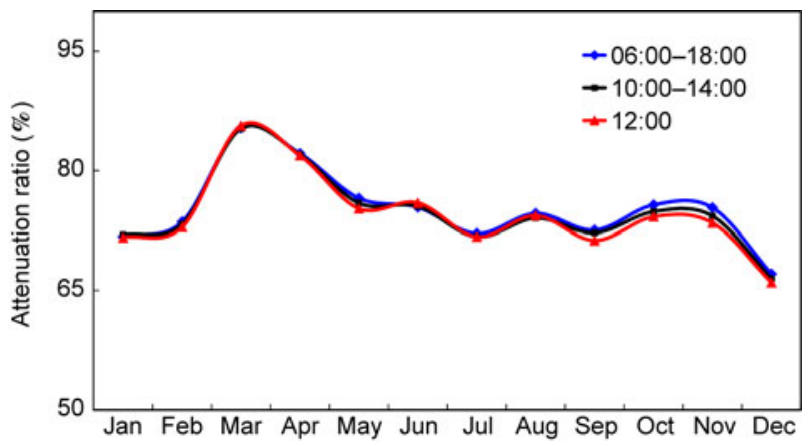

Figure 6 Monthly variation of surface UV radiation attenuation rate due to actual atmosphere $\mathrm{UV}_{\mathrm{AR}}$. composition. The observation data in cloud-free days must be applied to illustrate the attenuation of UV radiation due to atmospheric aerosols (in order to exclude the impact of cloud). Eppley TUVR type original pulsation data of high temporal resolution sampling (the average measured 5 times per minute as a sample) are analyzed in this paper, and the method in the reference by Long et al. [43] is used to distinguish cloudy days and cloud-free days. The analysis shows that there has no cloud-free weather all day in the late spring to summer, that is, May to August. There is more cloud-free weather in autumn and winter in climate conditions of Guangzhou. The cases in October, November, December and January, that is, the dry seasons when the data representation is better and the pollution is more serious in Guangzhou are focused in this paper.

The monthly variation of 295-385 nm UV radiation observed in cloud-free days is shown in Figure 7, from which it can be seen that in the dry season (October, November, December and January) the observed radiation average of 295-385 $\mathrm{nm}$ at 06:00-18:00, 10:00-14:00, 12:00 is $(9.5,7.8$, $8.0,7.3),(17.2,14.6,15.4,14.0),(19.3,17.3,18.2,15.4)$ $\mathrm{W} / \mathrm{m}^{2}$, respectively; the variation range of each month is very small, and the minimum, maximum and average are very close to each other, indicating that the UV radiation pulsation variation is small in cloud-free days. TUV in Figure 7 represents the corresponding spectral UV radiation calculated in the case of cloud-free and no-aerosol using the TUV model, which is consistent with Figure 5. Compare the strongest surface UV radiation calculated in the theoretical model with that derived in cloud-free days, and the difference between them is significant, which indicates that the attenuation of UV radiation due to atmospheric aerosols is fairly apparent.

The monthly variation of the attenuation rate of UV radiation due to atmospheric aerosols in cloud-free days is shown in Figure 8, from which it can be seen that the attenuation rate of 295-385 nm radiation due to average aerosols at noon 12:00 in the dry season (October, November, December, January) is $65 \%, 64 \%, 57 \%, 60 \%$, respectively, and the attenuation extent of 295-385 nm UV radiation due to aerosols is $62 \%$ averagely; the attenuation rate variation range is $54 \%-61 \%$ and the average is $58 \%$ in other months such as September, February, March and April. While the attenuation rate of $295-385 \mathrm{~nm}$ radiation due to average aerosols at 06:00-18:00 in the dry season (October, November, December, January) is $67 \%, 67 \%, 59 \%$, 62\%, respectively, and the average attenuation rate is $64 \%$; the attenuation rate variation range is $55 \%-63 \%$ and the average is $61 \%$ in other months such as September, February, March and April. Comparative analysis shows that the average attenuation rates of UV radiation due to atmospheric aerosols at noon 12:00 and the whole day 06:00-18:00 are very close to each other, which indicates that the longer radiation optical path caused by solar elevation angle variation makes the attenuation due to aerosols increase slightly, while the 

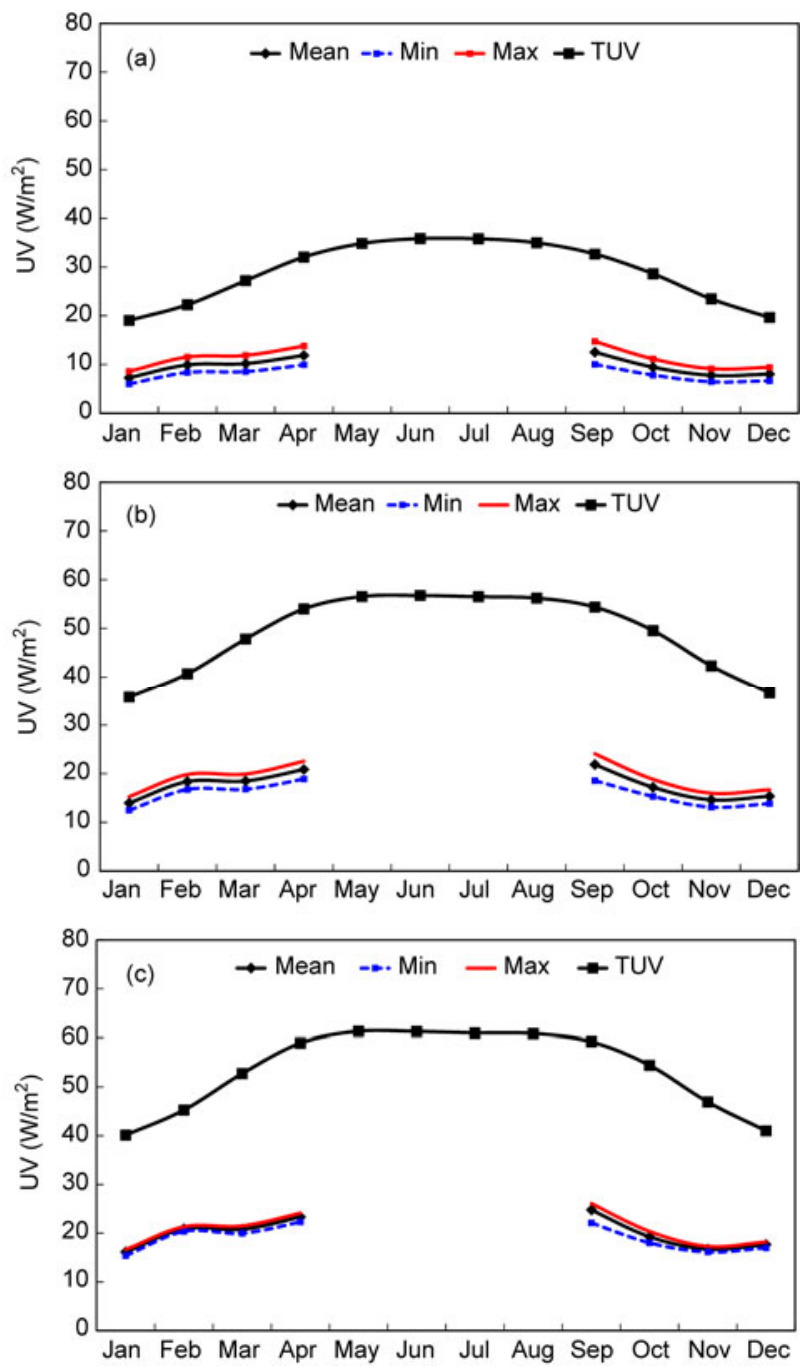

Figure 7 Monthly variation of the total UV radiation observed in cloud-free days. (a) 06:00-18:00; (b) 10:00-14:00; (c) 12:00.

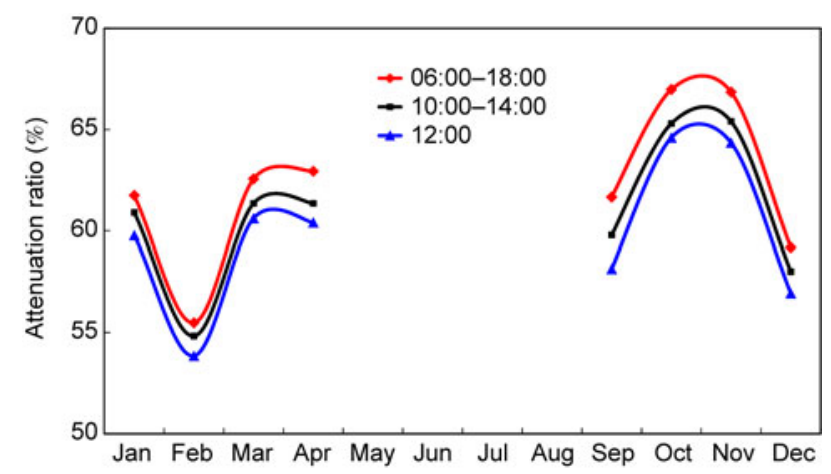

Figure 8 Monthly variation of the surface UV radiation attenuation rate due to aerosols in cloud-free days.

increase amplitude range is only in $3 \%$. Comparing with the monthly variation of UV radiation attenuation due to actual atmosphere shown in Figure 6, it can be seen that the attenuation rate difference between the two is small in the dry season (October, November, December, January), which indicates that the attenuation of UV radiation is mainly caused by aerosols in the dry season.

\section{Conclusions}

(1) The annual AOD average value of UV spectral region $340 \mathrm{~nm}$ in Guangzhou is 1.19 and the annual average occurrence frequency of $340 \mathrm{~nm}$ aerosol optical depth AOD>1 is $55 \%$. Analysis shows that the attenuation of $340 \mathrm{~nm}$ direct radiation due to atmospheric aerosols of urban agglomeration in Guangzhou is up to $68 \%$ at present.

(2) The attenuation of UV radiation due to the actual atmosphere in Guangzhou is apparent. The annual average attenuation of $295-385 \mathrm{~nm}$ UV radiation is $75 \%$; the average attenuation due to atmosphere in the dry season (October, November, December, January) is $72 \%$. These attenuations are mainly caused by scattering and absorption of clouds and aerosols.

(3) The average attenuation of 295-385 $\mathrm{nm}$ UV radiation due to aerosols at noon 12:00 and all day 06:00-18:00 in the dry season (October, November, December, January) is $62 \%$ and $64 \%$, respectively. Analysis shows that the attenuation rate of UV radiation due to aerosols at noon and that all day are very close to each other. The radiation optical path lengthening caused by solar elevation angle variation makes the increase amplitude of the attenuation rate due to aerosols vary in the range about $3 \%$.

This work was supported by the National Natural Science Foundation of China (41175117, 40875090 and 40375002), the National Basic Research Program (2011CB403403), the Science and Technology Foundation of Guangdong Province (2010A030200012) and the Science and Technology Innovation Team Plan of Guangdong Meteorological Bureau (201103).

1 Coakley J A, Cess R D, Yurevich F B. The effect of tropospheric aerosols on the earth's radiation budget: A parameterization for climate models. J Atmos Sci, 1983, 40: 116-138

2 Xia X A. Global MODIS aerosol optical thickness over land significantly higher (in Chinese). Chin Sci Bull (Chin Ver), 2006, 51: 22972303

3 Mao J T, Zhang J H, Huang M H. Summary comment on research of atmospheric aerosol in China (in Chinese). Acta Meteorol Sin, 2002, 60: 625-634

4 Li Z. Influence of absorbing aerosols on the inference of solar surface radiation budget and cloud absorption. J Clim, 1998, 11: 5-17

5 Zhou X J. Variation of Atmospheric Ozone and Its Climatic \& Environmental Impact in China (I) (in Chinese). Beijing: Meteorological Press, 1996

6 Deng X J, Zhou X J, Wu D, et al. Effect of atmospheric aerosol on surface ozone variation over the Pearl River Delta region. Sci China Earth Sci, 2011, 54: 744-752

7 WMO. The Global Atmosphere Watch (GAW) Strategic Plan 20012007, 2001

$8 \mathrm{Li}$ Z, Chen H, Cribb M, et al. Preface to special section: Overview of the East Asain Study of Tropospheric Aerosols: An International Regional Experiment (EAST-AIRE). J Geophys Res, 2007, D22S00, doi:10.1029/2007JD008853 
9 Xia X, Chen H, Li Z, et al. Significant reduction of surface solar irradiance induced by aerosols in a suburban region in northeastern China. J Geophys Res, 2007, 112: D22S02

10 Liu J, Xia X, Wang P, et al. Significant aerosol direct radiative effects during a pollution episode in northern China. Geophys Res Lett, 2007, doi:10.1016/j.atmosenv.2007.05.001

11 Li G H, Zhang R Y, Fan J W, et al. Impact of black carbon aerosol on photolysis and ozone. J Geophys Res, 2005, 110: D23206

12 Ralph E M, Bonyoung K, Alex G, et al. Model sensitivity evaluation for organic carbon using two multi-pollutant air quality models that simulate regional haze in the southeastern United States. Atmos Environ, 2006, 40: 4960-4972

13 Wu D, Mao J T, Deng X J, et al. Black carbon aerosols and their radiative properties in the Pearl River Delta region. Sci China Ser D-Earth Sci, 2009, 52, doi: 10.1007/s11430-009-0115-y

14 Dave J V. Effect of aerosols on the estimation of total ozone in an atmospheric column from the measurements of its ultraviolet radiance. J Atmos Sci, 1978, 35: 899-911

15 Anita B B. The effects of sunshine, cloudiness and haze on received ultraviolet radiation in New York. J Appl Meteorol, 1980, 19: 889-893

16 Richard H G, Gordon M H. Estimation of ultraviolet-B irradiance under variable cloud conditions. J Atmos Sci, 2000, 39: 904-916

17 Lyamani H, Olmo F J, Ntara A A, et al. Atmospheric aerosols during the 2003 heat wave in southeastern Spain II: Microphysical columnar properties and radiative forcing. Atmos Environ, 2006, 40: 6465-6476

18 Tie X, Madronich S, Walters S, et al. Effect of Clouds on photolysis and oxidants in the troposphere. J Geophys Res, 2003, 108: 4642

19 Tie X, Madronich S, Walters S, et al. Assessment of the global impact of aerosols on tropospheric oxidants. J Geophys Res, 2005, 110: D03204

20 An J L, Wang Y S, Li X, et al. Relationship between surface UV radiation and air pollution in Beijing (in Chinese). Environ Sci, 2008, 29: $1054-1058$

21 Zhang W, Shao D M. A Study of solar ultraviolet radiation influencing Shanghai (in Chinese). Meteorology, 2002, 28: 48-54

22 Bai J H, Huang G C, Hu F. The variation trends of ultraviolet radiation in clear sky during the last two decades in Beijing (in Chinese). $\mathrm{J}$ Atmos Sci, 2003, 27: 273-280

23 Zhu Q L, Yu G R, Cai F, et al. Spatialization research on ultraviolet radiation in China (in Chinese). Res Sci, 2005, 27: 108-113

24 Wang J, Hou H Y. Research of solar ultraviolet radiation in the Qingdao region (in Chinese). Period Ocean Univ Chin, 2006, 36: 671-676

25 Deng X J, Wu D, Tie X X, et al. Study on the effect of atmospheric aerosol on actinic flux and ozone in large city (Part I): Current research state abroad and at home and observed event (in Chinese). Guangdong Meteorol, 2006, 3: 10-17

26 Deng X J, Tie X X, Wu D, et al. Study on the effect of atmospheric aerosol on actinic flux and ozone in large city (Part II): Numerical test analyses (in Chinese). Guangdong Meteorol, 2006, 4: 5-11
27 Wu D, Deng X J. Environmental Meteorology and Special Meteorological Forecast (in Chinese). Beijing: Meteorological Press, 2001

28 Tang J, Wang B Z. The performance testing of domestic total UV insolation (II): Outdoor testing and comparison of similar products abroad (in Chinese). Acta En Solar Sin, 2005, 26: 313-320

29 Tan H B, Deng X J, Wu D, et al. The performance of TUVR ultraviolet radiometer (in Chinese). J Appl Meteorol Sci, 2008, 19: 367371

30 Kirk D K, Christophe P, Giulietta S F. Sun pointing error correction for sea deployment of the MICROTOPS II handheld sunphotometer. J Atmos Ocean Tech, 2003, 20: 767-771

31 Smirnov A, Holben B N, Eck T F, et al. Cloud screening and quality control algorithms for the AERONET database. Remote Sens Environ, 2000, 73: 337-349

32 Bi X Y, Wu D, Tan H B, et al. Application, calculation and calibration of microtops II sunphotometer. Meteorol Sci Tech, 2007, 35: 583-588

33 Tan H B, Wu D, Deng X J, et al. Observational study of aerosol optical depth in Guangzhou. Acta Sci Cir, 2009, 29: 1146-1155

34 Madronich S, Flocke S. Handbook of Environmental Chemistry. Heidelberg: Springer-Verlag 1999. 1-26

35 Mayer B, Fischer C B, Madronich S. Estimation of surface actinic flux from satellite (TOMS) ozone and cloud reflectivity measurements. Geophys Res Lett, 1998, 25: 4321-4324

36 Castro T, Madronich S, Rivale S, et al. The influence of aerosols on photochemical smog in Mexico city. Atmos Environ, 2001, 35: 1765-1772

37 Deng X J. The aerosol characterizations and its impacts on visibility and surface ozone in the Pearl River Delta Region (PRD) (in Chinese). Dissertation for the Doctoral Degree. Beijing: Peking University, 2008

38 Krzycin J W, Puchalski S. Aerosol impact on the surface UV radiation from the ground-based measurements taken at Belsk, Poland, 1980-1996. J Geophys Res, 1998, 13: 16175-16181

39 Papayannis A, Balis D, Bais A, et al. Role of urban and suburban aerosols on solar UV radiation over Athens, Greece. Atmos Environ, 1998, 32: 2193-2201

40 Koronakis P S, Sfantos G K, Paliatsos A G, et al. Interrelations of Vglobal/global/diffuse solar irradiance components and UV-global attenuation on air pollution episode days in Athens, Greece. Atmos Environ, 2002, 19: 3173-3181

41 Kalashnikova O V, Mills F P, Eldering A, et al. Application of satellite and ground-based data to investigate the UV radiative effects of Australian aerosols. Rem Sens Environ, 2007, 107: 65-80

42 Deng X J, Tie X, Zhou X J, et al. Effects of Southeast Asia biomass burning on aerosols and ozone concentrations over the Pearl River Delta (PRD) Region. Atmos Environ, 2008, 42: 8493-8501

43 Long C N, Ackerman T P. Identification of clear skies from broadband pyranometer measurements and calculation of downwelling shortwave cloud effects. J Geophys Res, 2000, 105: 15609-15626

Open Access This article is distributed under the terms of the Creative Commons Attribution License which permits any use, distribution, and reproduction in any medium, provided the original author(s) and source are credited. 